\title{
Low vitamin D status is associated with inflammation in patients with prostate cancer
}

\author{
Dong-Dong Xie ${ }^{1, *}$, Yuan-Hua Chen ${ }^{3, *}$, Shen $X u^{1, *}$, Cheng Zhang ${ }^{2}$, Da-Ming Wang ${ }^{1}$, \\ Hua Wang ${ }^{2}$, Lei Chen ${ }^{1}$, Zhi-Hui Zhang ${ }^{2}$, Mi-Zhen Xia ${ }^{4}$, De-Xiang Xu${ }^{2}$, De-Xin Yu ${ }^{1}$ \\ ${ }^{1}$ Department of Urology, Second Affiliated Hospital, Anhui Medical University, Hefei 230022, China \\ ${ }^{2}$ Department of Toxicology, Anhui Medical University, Hefei 230032, China \\ ${ }^{3}$ Department of Histology and Embryology, Anhui Medical University, Hefei 230032, China \\ ${ }^{4}$ Life Science College, Anhui Medical University, Hefei 230032, China \\ *These authors have contributed equally to this work \\ Correspondence to: De-Xin Yu, email: yudx_urology@126.com \\ De-Xiang Xu, email: xudex@126.com \\ Keywords: prostate cancer, vitamin D deficiency, inflammation, vitamin D receptor, nuclear factor kappa B p65 \\ Received: November 10,2016 Accepted: January 22, $2017 \quad$ Published: March 15, 2017
}

\section{ABSTRACT}

Vitamin D deficiency has been associated with increased risks of prostate cancer. Nevertheless, the mechanisms remain unclear. The aim of this study was to analyze the association among prostate cancer, vitamin D status and inflammation. Sixty patients with newly diagnosed prostate cancer and 120 age-matched controls were recruited for this study. Vitamin D status was evaluated and serum inflammatory molecules were measured. Serum 25-(OH)D was lower in patients with prostate cancer. Moreover, serum 25(OH)D was lower in patients with severe prostate cancer than patients with mild and moderate prostate cancer. By contrast, serum C-reactive protein (CRP) and interleukin (IL)-8, two inflammatory molecules, were elevated in patients with prostate cancer. Serum 25-(OH)D was negatively correlated with serum CRP and IL-8 in patients with prostate cancer. Additional analysis showed that the percentage of vitamin $D$ receptor positive nucleus in the prostate was reduced in patients with prostate cancer. By contrast, the percentage of nuclear factor kappa B p65-positive nucleus was elevated in patients with prostate cancer. Our results provide evidence that there is an association among prostate cancer, vitamin D deficiency and inflammatory signaling. Inflammation may be an important mediator for prostate cancer progression in patients with low vitamin D status.

\section{INTRODUCTION}

In Western countries, prostate cancer is the most common malignant tumor in men and a major cause of cancer deaths [1]. The incidence of prostate cancer differs between countries due to coverage of prostatespecific antigen (PSA) screening [2]. In China, the incidence of prostate cancer is rapidly increasing and especially in patients with obesity or diabetes [3, 4]. As androgen receptor (AR) signaling is a key pathway for the pathogenesis of prostate cancer, androgen-deprivation therapy remains the principal method for patients with locally advanced and metastatic prostate cancer [5]. Unfortunately, the majority of patients with advancedstage or metastatic cancer will ultimately progress to castration-resistant prostate cancer [6]. The mechanisms by which prostate cancer progresses to castrationresistant prostate cancer have been studied extensively [7]. Increasing evidence demonstrates that inflammation plays important roles in the pathogenesis of progression to castration-resistant prostate cancer [8].

Vitamin D is a secosteroid hormone and well-known for its classical actions in the maintenance of calcium uptake and bone metabolism $[9,10]$. Recently, numerous in vitro experiments demonstrated that $1,25-(\mathrm{OH}) 2 \mathrm{D} 3$, the active form of vitamin $\mathrm{D}$, inhibited the growth and differentiation of human prostate cancer cells [11-13]. A double-blinded clinical study found that vitamin D supplementation reduced prostate specific antigen (PSA) level and enhanced survival rate in patients with prostate 
cancer [14]. On the other hand, vitamin D receptor (VDR) polymorphisms were associated with the incidence of prostate cancer $[15,16]$. Several epidemiological reports showed that men with vitamin D deficiency had a higher risk of prostate cancer compared to men with vitamin D sufficiency [17-19]. Nevertheless, the mechanisms through which vitamin D deficiency elevates the risk of prostate cancer remain unclear.

Accumulating evidence demonstrates that vitamin D has an anti-inflammatory activity [20, 21]. Several studies suggest that vitamin D exerts its anti-inflammatory activity through suppressing nuclear factor kappa B (NF-кB) signaling [22-25]. Thus, we hypothesize that vitamin D3 inhibits the incidence and progression of prostate cancer through its anti-inflammatory effect. The present study aimed to investigate whether there was an association among prostate cancer, vitamin D status and inflammation in a hospital-based case-control study. If so, we were to further analyze the expression of VDR and NF- $\kappa \mathrm{B}$ p65 subunit in prostatic nuclei.

\section{RESULTS}

\section{Biochemical characteristics}

Biochemical characteristics were analyzed. As shown in Table 1, no significant difference in SBP and DBP, TES, ALT, Cr, UA, TG, TCH, fasting blood glucose, and serum phosphorus was observed between cases and controls. As expected, serum T-PSA was significantly increased in patients with prostate cancer as compared with control subjects (Table 1). In addition, serum LDH was slightly increased in patients with prostate cancer as compared with control subjects (Table 1). Interestingly, serum calcium level was lower in patients with prostate cancer than in controls (Table 1).

\section{Association between prostate cancer and vitamin D status}

Serum 25(OH)D concentration was analyzed in all subjects. As shown in Figure 1A, serum 25(OH)D in patients with prostate cancer was significantly lower than in controls. Multivariable logistic regression analysis was conducted to further evaluate the association between prostate cancer and serum 25(OH)D. As shown in Table 2, there was an inverse association between prostate cancer and serum 25(OH)D (adjusted OR: 0.785; 95\%CI: 0.718 , 0.858).

\section{Association between the severity of prostate cancer and vitamin D status}

According to Gleason score, prostate cancer patients were categorized into two groups: mild and moderate prostate cancer (Grade 1-2); severe prostate cancer
(Grade 3). As shown in Figure 1B, serum 25(OH)D was slightly lower in patients with Grade 3 prostate cancer than patients with Grade 1-2 prostate cancer. Similarly, according to serum PSA level, prostate cancer patients were stratified into two groups: mild and moderate prostate cancer (Grade 1-2); severe prostate cancer (Grade 3). As shown in Figure $1 \mathrm{C}$, serum $25(\mathrm{OH}) \mathrm{D}$ was markedly lower in patients with Grade 3 prostate cancer than patients with Grade 1-2 prostate cancer.

\section{Association between prostate cancer and inflammation}

Serum TNF- $\alpha$, CRP and IL-8 levelswere analyzed in patients with prostate cancer and controls. As shown in Table 3, no significant difference in serum TNF- $\alpha$ level was observed between patients with prostate cancer and controls. Interestingly, serum CRP and IL-8 levels were significantly higher in patients with prostate cancer than in controls (Table 3 ).

\section{Association between the severity of prostate cancer and inflammation}

According to Gleason score, prostate cancer patients were categorized into two groups: mild and moderate prostate cancer (Grade 1-2); severe prostate cancer (Grade 3). Results showed that no statistically significant difference in serum TNF- $\alpha$ and IL- 8 levels was observed between two groups (Table 3 ). Interestingly, serum CRP level was significantly increased in patients with Grade 3 prostate cancer than in patients with Grade 1-2 prostate cancer (Table 3). Similarly, according to serum PSA level, prostate cancer patients were stratified into two groups: mild and moderate prostate cancer (Grade 1-2); severe prostate cancer (Grade 3). Results showed that no significant difference in serum TNF- $\alpha$ and CRP levels was observed between two groups (Table 3 ). Interestingly, serum IL-8 level was significantly increased in patients with Grade 3 prostate cancer than patients with Grade 1-2 prostate cancer (Table 3).

\section{Association between vitamin D status and serum inflammatory molecules}

The correlation between serum 25-(OH)D and CRP levels was analyzed. As shown in Figure 2A, no significant correlation was observed between serum 25 $(\mathrm{OH}) \mathrm{D}$ and CRP levels in control subjects. Interestingly, serum 25-(OH)D was negatively correlated with serum CRP level in patients with prostate cancer (Figure 2B; $r=$ $0.286, P<0.05)$. The correlation between serum $25(\mathrm{OH})$ $\mathrm{D}$ and IL-8 levels was then analyzed. As shown in Figure $2 \mathrm{C}$, no significant correlation was observed between serum $25(\mathrm{OH}) \mathrm{D}$ and IL-8 levels in controls. Interestingly, there was an inverse correlation between serum 25(OH)D and 
Table 1: The demographic and biochemical characteristics between cases and controls

\begin{tabular}{|c|c|c|c|}
\hline & Controls & Cases & $P$ \\
\hline Subjects (n) & 120 & 60 & \\
\hline Years (years) & $65.35 \pm 7.76$ & $66.35 \pm 6.87$ & 0.3987 \\
\hline Height $(\mathrm{cm})$ & $166.51 \pm 6.75$ & $167.51 \pm 5.35$ & 0.3184 \\
\hline Weight (kg) & $62.36 \pm 5.63$ & $65.82 \pm 8.57$ & 0.0014 \\
\hline BMI $\left(\mathrm{kg} / \mathrm{m}^{2}\right)$ & $21.56 \pm 2.57$ & $24.98 \pm 2.39$ & $<0.0001$ \\
\hline $\mathrm{SBP}(\mathrm{mmHg})$ & $129.35 \pm 15.86$ & $131.76 \pm 13.41$ & 0.3139 \\
\hline DBP (mmHg) & $85.45 \pm 10.52$ & $87.15 \pm 11.26$ & 0.3195 \\
\hline T-PSA (ng/ml) & $3.70 \pm 2.36$ & $35.70 \pm 25.67$ & $<0.0001$ \\
\hline TES (nmol/ml) & $10.8 \pm 4.81$ & $10.66 \pm 5.39$ & 0.8651 \\
\hline $\operatorname{ALT}(\mathrm{U} / \mathrm{L})$ & $13.21 \pm 5.89$ & $14.93 \pm 6.82$ & 0.0977 \\
\hline AST (U/L) & $23.18 \pm 3.02$ & $25.09 \pm 6.22$ & 0.0270 \\
\hline $\mathrm{LDH}(\mathrm{U} / \mathrm{L})$ & $155.17 \pm 22.06$ & $198.65 \pm 66.23$ & $<0.0001$ \\
\hline $\mathrm{Cr}(\mu \mathrm{mol} / \mathrm{L})$ & $84.68 \pm 16.52$ & $88.17 \pm 16.21$ & 0.1780 \\
\hline $\mathrm{UA}(\mathrm{mmol} / \mathrm{L})$ & $385.35 \pm 93.95$ & $391.11 \pm 96.33$ & 0.7035 \\
\hline $\mathrm{TG}(\mathrm{mmol} / \mathrm{L})$ & $1.26 \pm 1.21$ & $1.22 \pm 0.87$ & 0.7999 \\
\hline $\mathrm{TCH}(\mathrm{mmol} / \mathrm{L})$ & $4.22 \pm 0.75$ & $4.13 \pm 0.67$ & 0.4157 \\
\hline GLU (mmol/L) & $5.59 \pm 1.21$ & $5.77 \pm 1.41$ & 0.3993 \\
\hline Calcium (mmol/L) & $2.09 \pm 0.13$ & $1.82 \pm 0.35$ & $<0.0001$ \\
\hline Phosphorus (mmol/L) & $1.12 \pm 0.26$ & $1.16 \pm 0.19$ & 0.2428 \\
\hline
\end{tabular}

Values are given as the mean \pm standard deviation.

BMI, body mass index; SBP, systolic blood pressure; DBP, diastolic blood pressure; T-PSA, total prostate specific antigen; $\mathrm{Cr}$, creatinine; UA, uric acid; ALT, alanine aminotransferase; AST, aspartate aminotransferase; LDH, lactate dehydrogenase; TG, triglyceride.

A

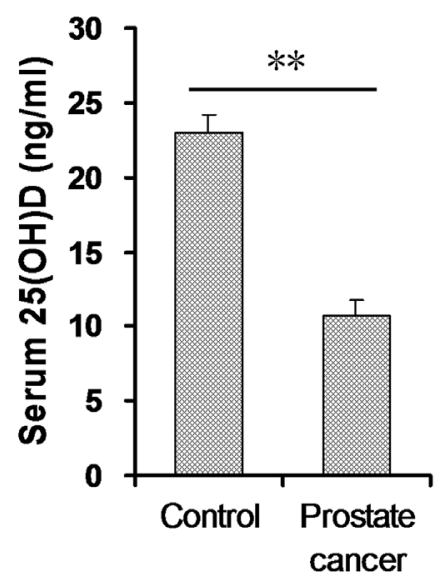

B

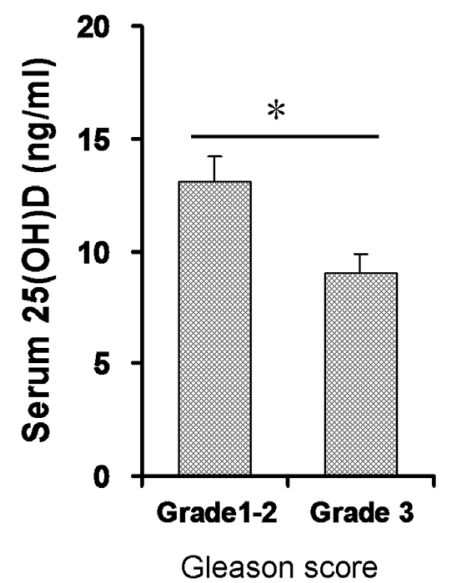

C

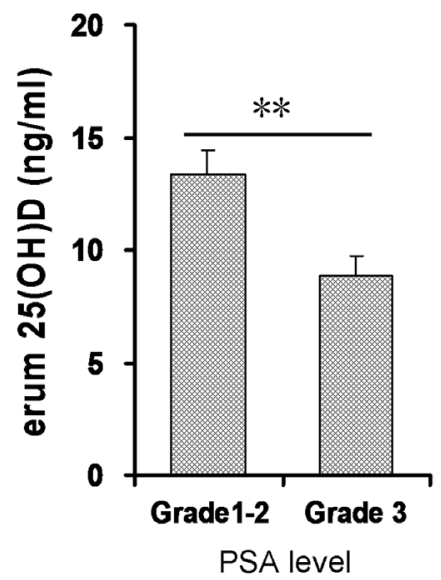

Figure 1: Association between prostate cancer and vitamin D status. Serum 25-(OH)D was measured by RIA. (A) Serum $25(\mathrm{OH}) \mathrm{D}$ level was compared between patients with prostate cancer and controls. $(\mathrm{N}=60$ for patients with prostate cancer; $\mathrm{N}=120$ for controls). (B) Patients with prostate cancer were divided into two groups according to Gleason score: mild and moderate prostate cancer $(n=34)$ and severe prostate cancer $(n=26)$. Serum 25(OH)D level was compared between two groups. (C) Patients with prostate cancer were divided into two groups according to serum PSA level: mild and moderate prostate cancer $(n=31)$ and severe prostate cancer ( $n=29)$. Serum 25(OH)D level was compared between two groups. All data were expressed as means \pm S.E.M. $* P<0.05 ; * * P<0.01$. 
Table 2: Multivariable logistic regression analysis correlation between prostate cancer and 25(OH)D

\begin{tabular}{lcccc}
\hline Variable & $\boldsymbol{\beta}$ & Wald & $\boldsymbol{P}$ & $\boldsymbol{O R}(\mathbf{9 5 \%} \boldsymbol{C . I . )}$ \\
\hline Unadjusted & -0.235 & 28.745 & $<0.001$ & $0.790(0.725,0.861)$ \\
Adjusted* & -0.242 & 28.440 & $<0.001$ & $0.785(0.718,0.858)$ \\
\hline
\end{tabular}

Note: $\beta$ : regression coefficient; Wald: Wald chi-square value; OR: odds ratio.

*Adjusted for BMI, AST and LDH

Table 3: Association between the severity of prostate cancer and inflammation

\begin{tabular}{|c|c|c|c|c|}
\hline & $\mathbf{n}$ & TNF- $\alpha(\mathrm{pg} / \mathrm{ml})$ & CRP (mg/l) & IL-8 (pg/ml) \\
\hline \multicolumn{5}{|l|}{ All subjects } \\
\hline Control & 120 & $15.87 \pm 1.66$ & $3.01 \pm 0.24$ & $68.94 \pm 4.46$ \\
\hline Prostate cancer & 60 & $15.48 \pm 1.66$ & $4.46 \pm 0.39 * *$ & $157.99 \pm 21.47 * *$ \\
\hline \multicolumn{5}{|c|}{ Grade according to Gleason score } \\
\hline Grade 1-2 & 34 & $14.49 \pm 1.36$ & $3.62 \pm 0.43$ & $143.56 \pm 16.13$ \\
\hline Grade 3 & 26 & $16.61 \pm 2.05$ & $5.13 \pm 0.25 \dagger$ & $174.52 \pm 24.51$ \\
\hline \multicolumn{5}{|c|}{ Grade according to PSA levels } \\
\hline Grade $1-2$ & 32 & $15.26 \pm 1.21$ & $4.22 \pm 0.28$ & $134.06 \pm 12.25$ \\
\hline Grade 3 & 28 & $15.68 \pm 2.06$ & $4.76 \pm 0.37$ & $188.58 \pm 19.56 \dagger$ \\
\hline
\end{tabular}

All data were expressed as means \pm S.E.M. ${ }^{* *} P<0.01$ compare with control; $\uparrow P<0.05$ compare with grade 1-2.
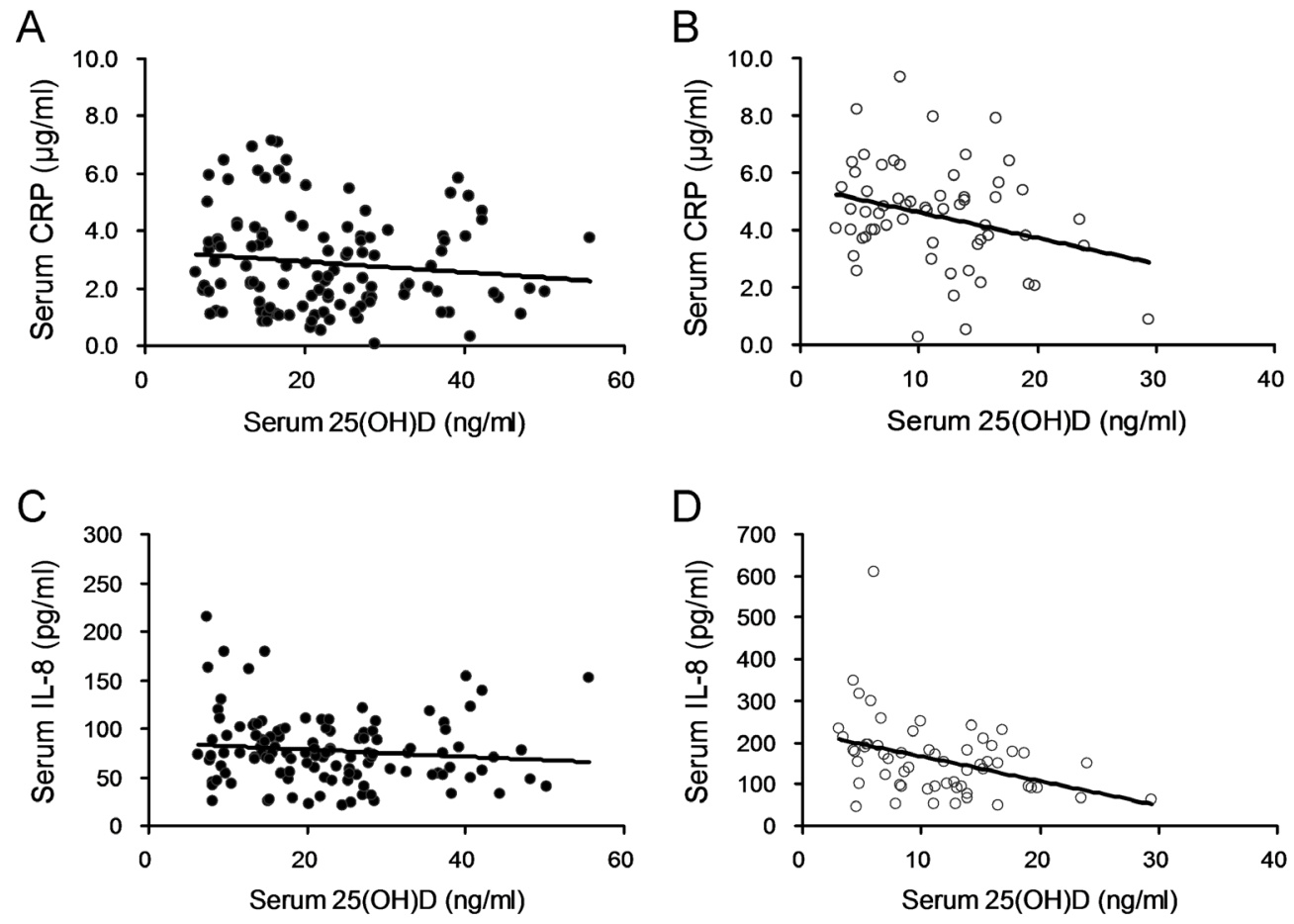

Figure 2: Correlation analysis between serum 25(OH)D and inflammation in patients with prostate cancer and controls. (A) Correlation analysis between serum 25(OH)D and CRP in control subjects. (B) Correlation analysis between serum 25(OH) $\mathrm{D}$ and CRP in patients with prostate cancer. (C) Correlation analysis between serum 25(OH)D and IL-8 in control subjects. (D) Correlation analysis between serum $25(\mathrm{OH}) \mathrm{D}$ and IL-8 in patients with prostate cancer. 
IL-8 levels in prostate cancer patients (Figure 2D; $r=$ $0.376, P<0.01)$.

\section{Prostatic NF-кB p65 and VDR in patients with prostate cancer and controls}

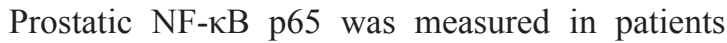
with prostate cancer and controls. As shown in Figure $3 \mathrm{~A}$, the number of p65-positive nucleus in prostate adenoepithelium was quite small in control subjects. Interestingly, the number of p65-positive nucleus in prostate adenoepithelium was markedly increased in patients with prostate cancer (Figure 3B). Prostatic VDR was then analyzed in patients with prostate cancer and controls. As shown in Figure 4A, numerous VDRpositive nuclei were observed in prostate adenoepithelium of controls. Interestingly, the number of VDR-positive nucleus in prostate adenoepithelium was significantly decreased in patients with prostate cancer (Figure 4B).

\section{DISCUSSION}

The present study analyzed the association among prostate cancer, vitamin D status and inflammation. Our results showed that serum $25-(\mathrm{OH}) \mathrm{D}$ was reduced in patients with prostate cancer. By contrast, serum CRP, a marker of systemic inflammation, was elevated in patients
A

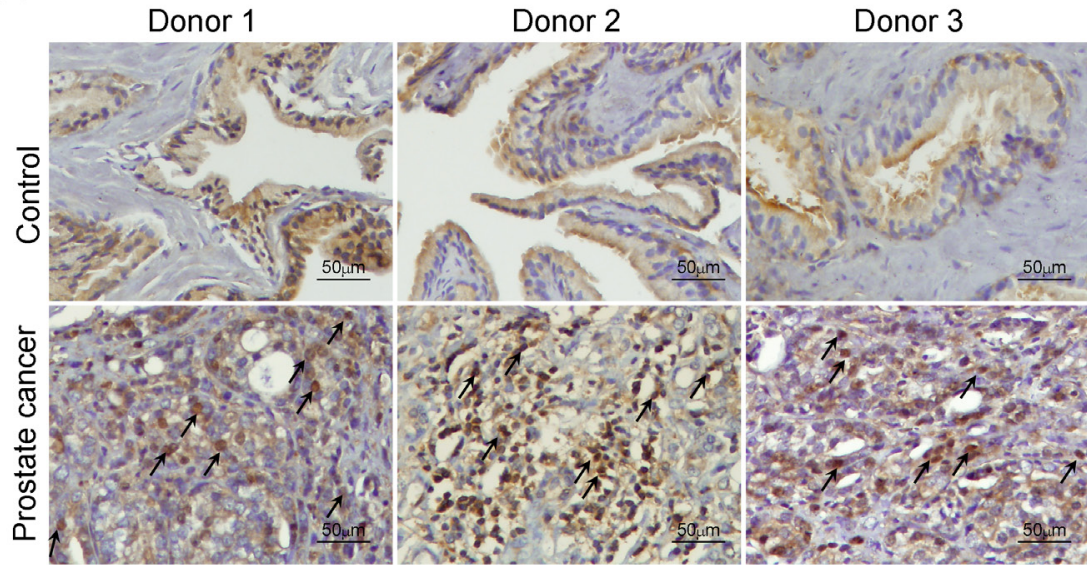

B

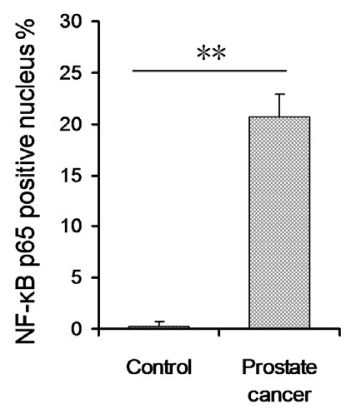

Figure 3: Prostatic NF-кB p65 in patients with prostate cancer and controls. (A) Prostatic NF- $\mathrm{BB}$ p65 was determined using

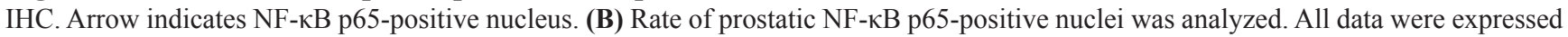
as means \pm S.E.M. $(\mathrm{N}=20$ for patients with prostate cancer; $\mathrm{N}=20$ for controls). $* * P<0.01$.

A

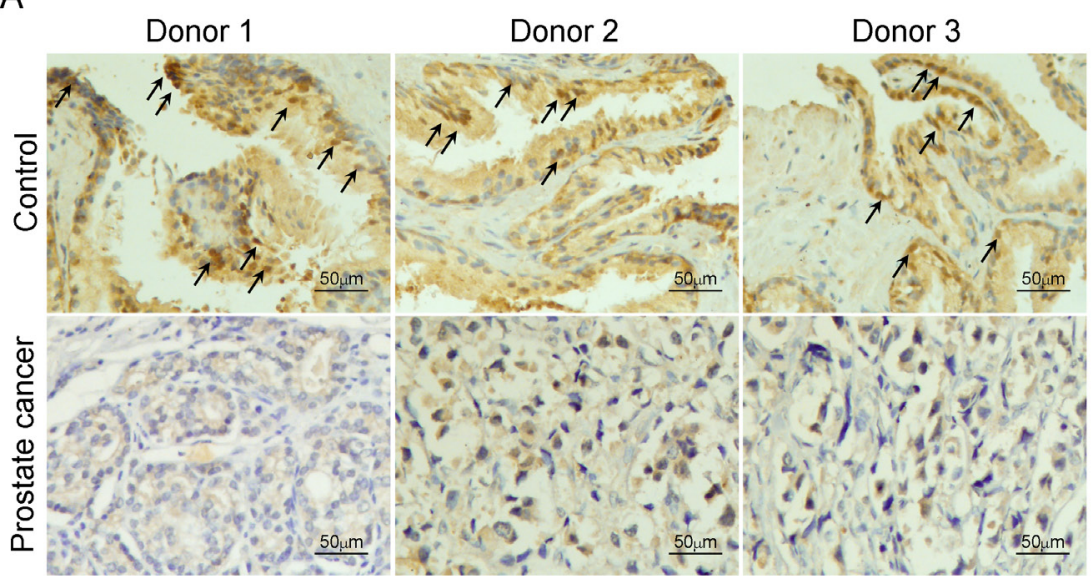

B

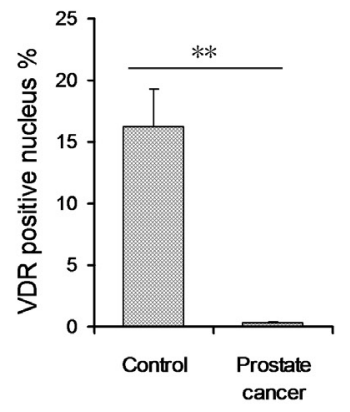

Figure 4: Prostatic VDR in patients with prostate cancer and controls. (A) Prostatic VDR was determined using IHC. Arrow indicates VDR-positive nucleus. (B) Rate of VDR-positive nuclei was analyzed. All data were expressed as means \pm S.E.M. (N=20 for patients with prostate cancer; $\mathrm{N}=20$ for controls). ${ }^{* *} P<0.01$. 
with prostate cancer. In addition, serum IL-8 level was also elevated in patients with prostate cancer. These results provide evidence for the first time that low vitamin $\mathrm{D}$ status is associated with inflammation in patients with prostate cancer.

Chronic inflammation promotes metastases and progression to castration-resistant prostate cancer [26, 27]. CRP could predict tumor aggressiveness and potential treatment efficacy in patients with prostate cancer [28]. According to an early report, CRP is an independent prognostic factor for overall survival of patients with castration-resistant prostate cancer treated with docetaxel [29]. A recent study showed that elevated CRP level was associated with poor prognosis in prostate cancer patients treated with radiotherapy [30]. Accumulating data demonstrate that IL-8 is expressed by prostate cancer cells in which it contributes to increased angiogenesis, metastasis, and progression toward castration and chemotherapy resistance $[31,32]$. An early study showed that IL-8 promoted androgen-independent proliferation of prostate cancer cells via inducing androgen receptor expression and activation [34]. Additional report indicated that IL-8 attenuated TRAIL- and chemotherapy-induced apoptosis through transcriptional regulation of c-FLIP in prostate cancer cells [34]. A recent study found that IL-8 sustained cell survival in PTEN-deficient prostate carcinoma [35]. The present study analyzed the levels of serum 25-(OH)D and inflammatory molecules in patients with different grades of prostate cancer. Our results showed that serum $25-(\mathrm{OH}) \mathrm{D}$ level was lower in patients with severe prostate cancer than in patients with mild and moderate prostate cancer. By contrast, serum CRP and IL-8 levels were higher in patients with Grade 3 prostate cancer than in patients with Grade 1-2 prostate cancer. These results suggest that low vitamin D status is associated with inflammation and the progression of prostate cancer.

Increasing evidence indicates that vitamin $\mathrm{D}$ has an anti-inflammatory activity [20]. According to an early report, vitamin D inhibited IL-8 production in TNF$\alpha$-stimulated human dermal fibroblasts [36]. A recent study found that vitamin D suppressed IL-8 production in bacterial virulence factors-stimulated monocytederived macrophages [37]. The present study analyzed the association between vitamin $\mathrm{D}$ status and serum inflammatory molecules in patients with prostate cancer. Although no significant correlation was observed between serum $25-(\mathrm{OH}) \mathrm{D}$ and inflammatory molecules in control subjects, serum 25-(OH)D was negatively correlated with serum CRP and IL-8 levels in patients with prostate cancer. These results suggest that inflammation may be a key mediator for prostate cancer progression in patients with low vitamin D status.

Several studies demonstrate that vitamin D blocks $\mathrm{NF}-\kappa \mathrm{B}$ activation $[24,38,39]$. Indeed, IL-8, responsible for the androgen-independent growth of advanced prostate cancer, is a downstream target of NF- $\kappa \mathrm{B}$ signaling [40]. On the other hand, $\mathrm{NF}-\kappa \mathrm{B}$ activation promotes tumor cell survival through its anti-apoptotic mechanism in prostate cancer [41]. In addition, NF- $\kappa B$ activation correlates with metastasis and prostate cancer progression to castrationresistant prostate cancer $[42,43]$. The present study measured prostatic VDR and NF- $\mathrm{B}$ p 65 subunit in patients with prostate cancer. As expected, nuclear VDR in the prostate was reduced in patients with prostate cancer. By contrast, prostatic NF- $\kappa \mathrm{B}$ signaling was activated in patients with prostate cancer. These results provide a mechanistic explanation for the association between prostate cancer and vitamin D deficiency.

The present study has several limitations. First, the present study did not observe whether vitamin D deficiency and inflammation promotes metastasis and progression of prostate cancer. Second, the present study did not clarify the mechanism through which vitamin $\mathrm{D}$ deficiency regulates prostatic $\mathrm{NF}-\kappa \mathrm{B}$ signaling and inflammation in patients with prostate cancer. Thus, additional study is required to investigate whether prostatic inflammation promotes progression to castrationresistant prostate cancer in patients with low vitamin D status. In addition, the mechanism through which vitamin D deficiency regulates prostatic inflammation and progression to castration-resistant prostate cancer needs to be explored in an in vitro experiment.

In summary, the present study investigated the association among prostate cancer, vitamin D status and inflammation. Our results showed that serum 25-(OH) $\mathrm{D}$ was decreased in patients with prostate cancer. By contrast, serum CRP and IL-8 were increased in patients with prostate cancer. We found that prostatic VDR signaling was attenuated in patients with prostate cancer. By contrast, prostatic NF- $\kappa \mathrm{B}$ signaling was activated in patients with prostate cancer. Our results provide evidence that there is an association among prostate cancer, vitamin $\mathrm{D}$ deficiency and inflammatory signaling.

\section{MATERIALS AND METHODS}

\section{Study participants}

This was a hospital-based case-control study using data from the Second Affiliated Hospital of Anhui Medical University in China between January 2013 and December 2014. In the present study, total 60 newly diagnosed patients with prostate cancer were recruited as cases. Prostate cancer were confirmed by histopathology. Controls were recruited from men undergoing physical examination at the Second Affiliated Hospital of Anhui Medical University. Each case was matched with two controls with regard to age (within 2 years). Potential controls with malignant tumor were excluded from this study. Serum samples of all cases and controls were collected at same season and stored at $-80^{\circ} \mathrm{C}$. The 
demographic characteristics between cases and controls were shown in Table 1. For measurement of prostatic VDR and NF- $\kappa \mathrm{B}$ p65, controls were recruited from histologically confirmed patients with benign prostatic hyperplasia at the Second Affiliated Hospital of Anhui Medical University. Each case was matched with one control with regard to age. All samples from cases and controls were collected at same season. In this study, total 20 controls and 20 cases were recruited for measurement of prostatic VDR and NF- $\kappa \mathrm{B}$ p65. The present study obtained ethics approval from the ethics committee of Anhui Medical University. Oral and written consents were obtained from all subjects.

\section{Grade of prostate cancer}

In the present study, Gleason score and PSA level were used to evaluate the severity of prostate cancer, respectively. According to Gleason score, prostate cancer patients were categorized into two groups: mild and moderate prostate cancer (Grade 1-2; Gleason score $\leq 7$ ); severe prostate cancer (Grade 3; Gleason score: 8-10). Similarly, according to serum PSA level, prostate cancer patients were stratified into two groups: mild and moderate prostate cancer (Grade 1-2; PSA $\leq 20 \mathrm{ng} / \mathrm{ml}$ ); severe prostate cancer (Grade 3; PSA > 20 ng/ml) [44, 45].

\section{Clinical and biochemical measurements}

Demographic and clinical characteristics were collected by a standard questionnaire, including age, education, occupation, history of cigarette smoking, alcohol intake and medications. Height, weight, systolic blood pressure (SBP) and diastolic blood pressure (DBP) were from record of physical examinations. Body mass index (BMI) was calculated. Venous blood was drawn in the morning with more than 8 hours fasting. Serum total prostate specific antigen (T-PSA), creatinine $(\mathrm{Cr})$, uric acid (UA), alanine aminotransferase (ALT), aspartate aminotransferase (AST), lactate dehydrogenase (LDH), triglyceride (TG), serum calcium, serum phosphorus, and fasting blood glucose were measured with automatic biochemical analyzer (KHBZY-1200).

\section{5-(OH)D measurement}

Serum 25-(OH)D concentration, as the most stable circulating form of this molecule, was measured by radioimmunoassay using a kit from Diasorin (DiaSorin Inc, Stillwater, MN, USA) following manufacturer's instructions [46]. Serum 25- $(\mathrm{OH}) \mathrm{D}$ concentration is expressed as $\mathrm{ng} / \mathrm{ml}$. Lower than $15 \mathrm{ng} / \mathrm{mL}$ of $25-(\mathrm{OH}) \mathrm{D}$ was defined as vitamin D deficiency [47].

\section{Enzyme-linked immunosorbent assay (ELISA)}

Commercial ELISA kits (R\&D Systems, Abingdon, Oxon, UK) were used to measure serum TNF- $\alpha, \mathrm{C}$-reactive protein (CRP) and IL-8 according to the manufacturer's protocol.

\section{Hematoxylin-eosin (HE) and immunohistochemistry}

Human prostate tissues from prostate cancer cases and benign prostatic hyperplasia controls were fixed in $4 \%$ formalin and embedded in paraffin according to the standard procedure. Paraffin embedded tissues were cut $5 \mu \mathrm{m}$ thick and stained with HE for histopathological analysis. For immunohistochemistry, paraffin-embedded prostate sections were deparaffinized and rehydrated in a graded ethanol series. After antigen retrieval and quenching of endogenous peroxidase, sections were incubated with NF- $\kappa$ B p65 or VDR monoclonal antibodies (Santa Cruz, CA, USA, 1:200 dilution) at $4{ }^{\circ} \mathrm{C}$ overnight. The color reaction was developed with HRP-linked polymer detection system and counterstaining with hematoxylin. The number of positive nuclei and total nuclei were counted in twelve randomly selected fields from each slide at a magnification of $\times 400$. The percentage of positive nuclei was calculated as a percentage of positive nuclei relative to the total nuclei.

\section{Statistical analysis}

SPSS version 16.0 statistical package was used for statistical analyses. The difference in continuous variables between two independent groups was compared using two independent sampling t test or the Mann-Whitney U-test. Comparative analyses of categorical variables were carried out by the chi-square test. Multivariable logistic regression was carried out to identify the associations between $25(\mathrm{OH}) \mathrm{D}$ and prostate cancer. The relationship between 25(OH)D concentration and IL-8 and CRP levels were analyzed using scatter plots and linear correlation. A $P$ value of less than 0.05 was considered statistically significant.

\section{ACKNOWLEDGMENTS}

This study was supported by National Natural Science Foundation of China $(81471467,81630084)$.

\section{CONFLICTS OF INTEREST}

The authors have declared that no competing interests exist. 


\section{Author's contributions}

De-Xin Yu and De-Xiang Xu conceived study. Dong-Dong Xie and Shen Xu collected data and carried out experiments. Dong-Dong Xie, Yuan-Hua Chen, Shen $\mathrm{Xu}$, Cheng Zhang, Da-Ming Wang, Hua Wang, Lei Chen, Zhi-Hui Zhang and Mi-Zhen Xia carried out experiments and analyzed data. De-Xiang Xu and Yuan-Hua Chen wrote paper. All authors read and approved the final manuscript.

\section{REFERENCES}

1. Attard G, Parker C, Eeles RA, Schröder F, Tomlins SA, Tannock I, Drake CG, de Bono JS. Prostate cancer. Lancet. 2016; 387:70-82. doi: 10.1016/S0140-6736(14)61947-4.

2. Hayes JH, Barry MJ. Screening for prostate cancer with the prostate-specific antigen test: a review of current evidence. JAMA. 2014; 311:1143-9. doi: 10.1001/jama.2014.2085.

3. Hu MB, Bai PD, Wu YS, Zhang LM, Xu H, Na R, Jiang HW, Ding Q. Higher body mass index increases the risk for biopsy-mediated detection of prostate cancer in Chinese men. PLoS One. 2015; 10:e0124668. doi: 10.1371/journal. pone. 0124668 .

4. Wang M, Hu RY, Wu HB, Pan J, Gong WW, Guo LH, Zhong JM, Fei FR, Yu M. Cancer risk among patients with type 2 diabetes mellitus: a population-based prospective study in China. Sci Rep. 2015; 5:11503. doi: 10.1038/ srep11503.

5. Ferraldeschi R, Welti J, Luo J, Attard G, de Bono JS. Targeting the androgen receptor pathway in castrationresistant prostate cancer: progresses and prospects. Oncogene. 2015; 34:1745-57. doi: 10.1038/onc.2014.115.

6. Fallowfield L, Payne H, Jenkins V. Patient-reported outcomes in metastatic castration-resistant prostate cancer. Nat Rev Clin Oncol. 2016; 13:643-50. doi: 10.1038/ nrclinonc.2016.100.

7. Wadosky KM, Koochekpour S. Molecular mechanisms underlying resistance to androgen deprivation therapy in prostate cancer. Oncotarget. 2016; 7:64447-70. doi: 10.18632/oncotarget.10901.

8. Gueron G, De Siervi A, Vazquez E. Advanced prostate cancer: reinforcing the strings between inflammation and the metastatic behavior. Prostate Cancer Prostatic Dis. 2012; 15:213-21. doi: 10.1038/pcan.2011.64.

9. Elder CJ, Bishop NJ. Rickets. Lancet. 2014; 383:1665-76. doi: 10.1016/S0140-6736(13)61650-5.

10. Munns CF, Shaw N, Kiely M, Specker BL, Thacher TD, Ozono K, Michigami T, Tiosano D, Mughal MZ, Mäkitie O, Ramos-Abad L, Ward L, DiMeglio LA, et al. Global Consensus Recommendations on Prevention and Management of Nutritional Rickets. J Clin Endocrinol Metab. 2016; 101:394-415. doi: 10.1210/jc.2015-2175.
11. Bernichtein S, Pigat N, Barry Delongchamps N, Boutillon F, Verkarre V, Camparo P, Reyes-Gomez E, Méjean A, Oudard SM, Lepicard EM, Viltard M, Souberbielle JC, Friedlander $\mathrm{G}$, et al. Vitamin D3 prevents calcium-induced progression of early-stage prostate tumors by counteracting TRPC6 and calcium sensing receptor upregulation. Cancer Res. 2017; 77:355-65. doi: 10.1158/0008-5472.CAN-16-0687.

12. Luo W, Yu WD, Ma Y, Chernov M, Trump DL, Johnson CS. Inhibition of protein kinase CK2 reduces Cyp24a1 expression and enhances 1,25-dihydroxyvitamin $\mathrm{D}(3)$ antitumor activity in human prostate cancer cells. Cancer Res. 2013;73:2289-97. doi: 10.1158/0008-5472. CAN-12-4119.

13. Koike H, Morikawa Y, Sekine Y, Matsui H, Shibata Y, Suzuki K. Survivin is associated with cell proliferation and has a role in 1a,25-dihydroxyvitamin D3 induced cell growth inhibition in prostate cancer. J Urol. 2011; 185:1497-503. doi: 10.1016/j.juro.2010.12.005.

14. Beer TM, Ryan CW, Venner PM, Petrylak DP, Chatta GS, Ruether JD, Redfern CH, Fehrenbacher L, Saleh MN, Waterhouse DM, Carducci MA, Vicario D, Dreicer R, et al. Double-blinded randomized study of high-dose calcitriol plus docetaxel compared with placebo plus docetaxel in androgen-independent prostate cancer: a report from the ASCENT Investigators. J Clin Oncol. 2007; 25:669-74. doi: 10.1200/JCO.2006.06.8197.

15. Cheteri MB, Stanford JL, Friedrichsen DM, Peters MA, Iwasaki L, Langlois MC, Feng Z, Ostrander EA. Vitamin $\mathrm{D}$ receptor gene polymorphisms and prostate cancer risk. Prostate. 2004; 59:409-18. doi: 10.1002/pros.20001.

16. Kang S, Zhao Y, Liu J, Wang L, Zhao G, Chen X, Yao A, Zhang L, Zhang X, Li X. Association of itamin D receptor Fok I polymorphism with the risk of prostate cancer: a meta-analysis. Oncotarget. 2016; 7:77878-89. doi: 10.18632/oncotarget.12837.

17. Tuohimaa P, Tenkanen L, Ahonen M, Lumme S, Jellum E, Hallmans G, Stattin P, Harvei S, Hakulinen T, Luostarinen T, Dillner J, Lehtinen M, Hakama M. Both high and low levels of blood vitamin D are associated with a higher prostate cancer risk: a longitudinal, nested case-control study in the Nordic countries. Int J Cancer. 2004;108:1048. doi:10.1002/ijc.11375.

18. Ahonen MH, Tenkanen L, Teppo L, Hakama M, Tuohimaa P. Prostate cancer risk and prediagnostic serum 25-hydroxyvitamin D levels (Finland). Cancer Causes Control. 2000;11:847-52.

19. Nelson SM, Batai K, Ahaghotu C, Agurs-Collins T, Kittles RA. Association between Serum 25-Hydroxy-Vitamin D and Aggressive Prostate Cancer in African American Men. Nutrients. 2016; 9: 12. doi: 10.3390/nu9010012.

20. Krishnan AV, Feldman D. Mechanisms of the anti-cancer and anti-inflammatory actions of vitamin D. Annu Rev Pharmacol Toxicol. 2011; 51:311-36. doi: 10.1146/ annurev-pharmtox-010510-100611. 
21. Tan ZX, Chen YH, Xu S, Qin HY, Wang H, Zhang $\mathrm{C}, \mathrm{Xu} \mathrm{DX}$, Zhao H. Calcitriol inhibits tumor necrosis factor alpha and macrophage inflammatory protein-2 during lipopolysaccharide-induced acute lung injury in mice. Steroids. 2016; 112:81-7. doi: 10.1016/j. steroids.2016.05.005.

22. Dáňová K, Klapetková A, Kayserová J, Šedivá A, Špíšek R, Jelínková LP. NF-kB, p38 MAPK, ERK1/2, mTOR, STAT3 and increased glycolysis regulate stability of paricalcitol/ dexamethasone-generated tolerogenic dendritic cells in the inflammatory environment. Oncotarget. 2015; 6:14123-38. doi: 10.18632/oncotarget.4234.

23. Fitch N, Becker AB, HayGlass KT. Vitamin D [1, 25(OH)2D3] Differentially Regulates Human Innate Cytokine Responses to Bacterial versus Viral Pattern Recognition Receptor Stimuli. J Immunol. 2016; 196:296572. doi: 10.4049/jimmunol.1500460.

24. Chen YH, Yu Z, Fu L, Wang H, Chen X, Zhang C, Lv ZM, $\mathrm{Xu}$ DX. Vitamin D3 inhibits lipopolysaccharide-induced placental inflammation through reinforcing interaction between vitamin D receptor and nuclear factor kappa B p65 subunit. Sci Rep. 2015; 5:10871. doi: 10.1038/srep10871.

25. Xu S, Chen YH, Tan ZX, Xie DD, Zhang C, Zhang ZH, Wang H, Zhao H, Yu DX, Xu DX. Vitamin D3 pretreatment regulates renal inflammatory responses during lipopolysaccharide-induced acute kidney injury. Sci Rep. 2015; 5:18687. doi: 10.1038/srep18687.

26. Liu Q, Li A, Tian Y, Wu JD, Liu Y, Li T, Chen Y, Han X, Wu K. The CXCL8-CXCR1/2 pathways in cancer. Cytokine Growth Factor Rev. 2016; 31:61-71. doi: 10.1016/j. cytogfr.2016.08.002.

27. Santoni M, Piva F, Scarpelli M, Cheng L, Lopez-Beltran A, Massari F, Iacovelli R, Berardi R, Santini D, Montironi $\mathrm{R}$. The origin of prostate metastases: emerging insights. Cancer Metastasis Rev. 2015; 34:765-73. doi: 10.1007/ s10555-015-9597-6.

28. Saito K, Kihara K. C-reactive protein as a biomarker for urological cancers. Nat Rev Urol. 2011; 8:659-66. doi: 10.1038/nrurol.2011.145.

29. Ito M, Saito K, Yasuda Y, Sukegawa G, Kubo Y, Numao N, Kitsukawa S, Urakami S, Yuasa T, Yamamoto S, Yonese J, Fukui I. Prognostic impact of C-reactive protein for determining overall survival of patients with castrationresistant prostate cancer treated with docetaxel. Urology. 2011; 78:1131-5. doi: 10.1016/j.urology.2011.07.1416.

30. Thurner EM, Krenn-Pilko S, Langsenlehner U, Stojakovic T, Pichler M, Gerger A, Kapp KS, Langsenlehner T. The elevated C-reactive protein level is associated with poor prognosis in prostate cancer patients treated with radiotherapy. Eur J Cancer. 2015; 51:610-9. doi: 10.1016/j. ejca.2015.01.002.

31. Murphy C, McGurk M, Pettigrew J, Santinelli A, Mazzucchelli R, Johnston PG, Montironi R, Waugh DJ. Nonapical and cytoplasmic expression of interleukin-8, CXCR1, and CXCR2 correlates with cell proliferation and microvessel density in prostate cancer. Clin Cancer Res. 2005; 11:411-7. doi: 10.1158/1078-0432.CCR-04-1518.

32. Araki S, Omori Y, Lyn D, Singh RK, Meinbach DM, Sandman Y, Lokeshwar VB, Lokeshwar BL. Interleukin-8 is a molecular determinant of androgen independence and progression in prostate cancer. Cancer Res. 2007; 67:685462. doi: 10.1158/0008-5472.CAN-07-1162.

33. Seaton A, Scullin P, Maxwell PJ, Wilson C, Pettigrew J, Gallagher R, O'Sullivan JM, Johnston PG, Waugh DJ. Interleukin-8 signaling promotes androgenindependent proliferation of prostate cancer cells via induction of androgen receptor expression and activation. Carcinogenesis. 2008; 29:1148-56. doi: 10.1093/carcin/ bgn 109.

34. Wilson C, Wilson T, Johnston PG, Longley DB, Waugh DJ. Interleukin-8 signaling attenuates TRAIL- and chemotherapy-induced apoptosis through transcriptional regulation of c-FLIP in prostate cancer cells. Mol Cancer Ther 2008; 7:2649-61. doi: 10.1158/1535-7163. MCT-08-0148.

35. Maxwell PJ, Coulter J, Walker SM, McKechnie M, Neisen J, McCabe N, Kennedy RD, Salto-Tellez M, Albanese C. Potentiation of inflammatory CXCL8 signalling sustains cell survival in PTEN-deficient prostate carcinoma. Eur Urol. 2013; 64:177-88. doi: 10.1016/j.eururo.2012.08.032.

36. Fukuoka M, Ogino Y, Sato H, Ohta T, Komoriya K. Regulation of RANTES and IL-8 production in normal human dermal fibroblasts by active vitamin D3 (tacalcitol). Br J Pharmacol. 1998; 124:1433-8. doi: 10.1038/ sj.bjp.0701988.

37. Dauletbaev N, Herscovitch K, Das M, Chen H, Bernier J, Matouk E, Bérubé J, Rousseau S, Lands LC. Downregulation of IL-8 by high-dose vitamin D is specific to hyperinflammatory macrophages and involves mechanisms beyond up-regulation of DUSP1. Br J Pharmacol. 2015; 172:4757-71. doi: 10.1111/bph.13249.

38. D'Ambrosio D, Cippitelli M, Cocciolo MG, Mazzeo D, Di Lucia P, Lang R, Sinigaglia F, Panina-Bordignon P. Inhibition of IL-12 production by 1,25-dihydroxyvitamin D3. Involvement of NF-kappaB downregulation in transcriptional repression of the p40 gene. J Clin Invest. 1998; 101:252-62. doi: 10.1172/JCI1050.

39. Wang Q, He Y, Shen Y, Zhang Q, Chen D, Zuo C, Qin J, Wang H, Wang J, Yu Y. Vitamin D inhibits COX-2 expression and inflammatory response by targeting thioesterase superfamily member 4. J Biol Chem. 2014; 289:11681-94. doi: 10.1074/jbc.M113.517581.

40. Xu Y, Josson S, Fang F, Oberley TD, St Clair DK, Wan XS, Sun Y, Bakthavatchalu V, Muthuswamy A, St Clair WH. RelB enhances prostate cancer growth: implications for the role of the nuclear factor-kappaB alternative pathway in tumorigenicity. Cancer Res. 2009; 69:3267-71. doi: 10.1158/0008-5472.CAN-08-4635.

41. Nguyen DP, Li J, Yadav SS, Tewari AK. Recent insights into NF- $\mathrm{B}$ signalling pathways and the link between 
inflammation and prostate cancer. BJU Int. 2014; 114:16876. doi: 10.1111/bju.12488.

42. Jin R, Yamashita H, Yu X, Wang J, Franco OE, Wang Y, Hayward SW, Matusik RJ. Inhibition of NF-kappa B signaling restores responsiveness of castrate-resistant prostate cancer cells to anti-androgen treatment by decreasing androgen receptor-variant expression. Oncogene. 2015; 34:3700-10. doi: 10.1038/onc.2014.302.

43. Jin R, Yi Y, Yull FE, Blackwell TS, Clark PE, Koyama T, Smith JA Jr, Matusik RJ. NF- $\kappa B$ gene signature predicts prostate cancer progression. Cancer Res. 2014; 74:2763-72. doi: 10.1158/0008-5472.CAN-13-2543.

44. Zhao SG, Chang SL, Spratt DE, Erho N, Yu M, Ashab HA, Alshalalfa M, Speers C, Tomlins SA, Davicioni E, Dicker AP, Carroll PR, Cooperberg MR, et al. Development and validation of a 24-gene predictor of response to postoperative radiotherapy in prostate cancer: a matched, retrospective analysis. Lancet Oncol. 2016; 17: 1612-20. doi: 10.1016/S1470-2045(16)30491-0.
45. Bruce HM, Stricker PD, Gupta R, Savdie RR, Haynes AM, Mahon KL, Lin HM, Kench JG, Horvath LG. Loss of AZGP1 as a Superior Predictor of Relapse in MarginPositive Localized Prostate Cancer. Prostate. 2016; 76:1491-500. doi: 10.1002/pros.23233.

46. Chen YH, Fu L, Hao JH, Yu Z, Zhu P, Wang H, Xu YY, Zhang C, Tao FB, Xu DX. Maternal vitamin D deficiency during pregnancy elevates the risks of small for gestational age and low birth weight infants in Chinese population. J Clin Endocrinol Metab. 2015; 100:1912-9. doi: 10.1210/ jc.2014-4407.

47. Scragg RK, Camargo CA Jr, Simpson RU. Relation of serum 25-hydroxyvitamin D to heart rate and cardiac work (from the National Health and Nutrition Examination Surveys). Am J Cardiol. 2010; 105:122-8. doi: 10.1016/j. amjcard.2009.08.661. 